\title{
Avaliação da eficiência do tratamento de esgoto doméstico pelo teste do micronúcleo em Oreochromis niloticus (Cichlidae)
}

\author{
Evaluation of the domestic wastewater treatment efficiency \\ by micronucleus test on Oreochromis niloticus (Cichlidae)
}

\section{Anita Martins Fontes Del-Guercio', Cintya Aparecida Christofoletti' ${ }^{2}$, Carmem Silvia Fontanetti ${ }^{3}$}

ㅁ

\begin{abstract}
RESUMO
Este estudo teve por objetivo avaliar a eficiência no tratamento do esgoto doméstico de uma cidade do interior paulista, pela análise de micronúcleos e anormalidades nucleares nos eritrócitos de tilápias expostas ao efluente bruto e ao tratado. Duas coletas foram realizadas: uma na estação chuvosa e outra na estação seca. Foram utilizados três aquários de $20 \mathrm{~L}$ nos experimentos, com cinco peixes cada. No primeiro, os animais foram expostos à água de poço artesiano (controle negativo); no segundo, ao esgoto bruto diluído; no terceiro, ao esgoto após tratamento. Decorrido o tempo de exposição (72 h), coletou-se o sangue desses animais para obtenção de lâminas de esfregaço. Os resultados obtidos mostraram efeitos genotóxicos e mutagênicos do efluente bruto, em ambas as coletas; porém, esses efeitos não foram significativos após o tratamento do esgoto, o que mostra que o processo utilizado no tratamento foi eficiente para minimizar tais efeitos.
\end{abstract}

Palavras-chave: tilápia; genotoxicidade; mutagenicidade; esgoto doméstico; reator anaeróbio de fluxo ascendente e de manta de lodo.

\begin{abstract}
This study aimed at evaluating the efficiency in the domestic wastewater treatment from a city of Sao Paulo State (Brazil), by micronuclei and nuclear abnormalities analysis in erythrocytes of tilapias exposed to raw and treated wastewater. Two samples were collected. Three aquariums of $20 \mathrm{~L}$, with five fish each, were used in the bioassays. In the first, the animals were exposed to the artesian water (negative control); in the second, to the diluted raw wastewater; and in the third, to after wastewater treatment. After the exposure time ( $72 \mathrm{~h}$ ), the blood was collected for preparing the smear slides. The results showed genotoxic and mutagenic effects of the raw wastewater in both samples, showing that the process used was efficient to minimize these effects.
\end{abstract}

Keywords: tilapia; genotoxicity, mutagenicity; domestic wastewater; upflow anaerobic sludge Blanket.

\section{INTRODUÇÃO}

Envolvendo processos de captação, tratamento e distribuição da água e esgoto, o saneamento básico constitui um dos mais importantes setores dentro do serviço público, e é um fator determinante para a qualidade de vida, uma vez que o consumo direto ou indireto de água contaminada pode causar sérios danos aos organismos. Logo, a contaminação aquática por dejetos domésticos e industriais caracteriza uma das maiores preocupações de saúde pública (MORAES \& JORDÃO, 2002; MARIA et al., 2003).

Os componentes presentes nas descargas de dejetos domésticos e industriais podem provocar alterações bioquímicas e genotóxicas em organismos aquáticos. Por essa razão, o uso de bioindicadores, tais como os peixes, são adequados para se estudar os efeitos desses poluentes no ambiente (RUSSO et al., 2004). Peixes e moluscos acumulam poluentes diretamente das águas contaminadas e/ou indiretamente, pela ingestão de organismos contaminados, já que desempenham diferentes papéis na cadeia trófica. Logo, são capazes de bioacumular, de forma direta, contaminantes dissolvidos na água (MINISSI et al., 1996; DAVID \& FONTANETTI, 2005; MATSUMOTO et al., 2006).

O teste do micronúcleo tem sido aplicado com sucesso em eritrócitos de peixes, com o intuito de avaliar a mutagenicidade de poluentes ambientais e de diferentes compostos químicos (GRISOLIA \& STARLING, 2001; SOUZA \& FONTANETTI, 2006; CHRISTOFOLETTI, 2008;

'Licenciada e Bacharel em Ciências Biológicas pela Universidade Estadual Paulista "Júlio de Mesquita Filho" (UNESP) - Rio Claro (SP), Brasil.

2Doutora em Biologia Celular e Molecular pela UNESP - Rio Claro (SP), Brasil.

${ }^{3}$ Doutora em Zoologia e Professora adjunta da UNESP - Rio Claro (SP), Brasil.

Endereço para correspondência: Carmem Silvia Fontanetti - Avenida 24-A, 1515 - Bela Vista - 13506-900 - Rio Claro (SP), Brasil - E-mail: fontanet@rc.unesp.br

Recebido em: 03/11/11 - Aceito em: 14/10/16 - Reg. ABES: 73709 
VENTURA et al., 2007; HOSHINA et al., 2008; FONTANETTI et al., 2012). Recentemente, também tem sido observada a presença de alterações nucleares em células expostas a substâncias com potencial mutagênico (ÇAVAS \& ERGENE-GÖZÜKARA, 2005). Essas alterações, descritas por Carrasco et al. (1990) segundo o seu aspecto, apresentam problemas quanto à sua análise, uma vez que não há um consenso sobre os tipos de irregularidades da morfologia nuclear que podem ser consideradas análogas ao micronúcleo, isto é, resultantes da ação de um agente mutagênico, uma vez que os mecanismos de formação de tais lesões ainda não estão totalmente esclarecidos (AYLLÓN \& GARCIA-VASQUEZ, 2000; ÇAVAS \& ERGENE-GÖZÜKARA, 2003). Entretanto, de acordo com a literatura, parecem estar relacionados com falhas na divisão celular e/ou processos de genotoxicidade e/ou mutagenicidade (HAM \& CORMACK, 1991; FENECH, 2000), sendo, portanto, complementares na análise de micronúcleos (SERRANO-GARCIA \& MONTERO-MONTOYA, 2001; FENECH \& CROTT, 2002; ÇAVAS \& ERGENE-GÖZÜKARA, 2005; SOUZA \& FONTANETTI, 2006; HOSHINA et al., 2008).

O presente trabalho teve por objetivo avaliar os potenciais genotóxico e mutagênico de um efluente doméstico de uma cidade do interior de São Paulo, antes e após seu tratamento. Para tal avaliação, o teste do micronúcleo associado às anormalidades nucleares foi aplicado em eritrócitos de peixes da espécie Oreochromis niloticus (Cichlidae) expostos a tais efluentes.

\section{MATERIAL E MÉTODOS}

\section{Caracterização da Área de Estudo e Sistema de Tratamento do Esgoto}

O efluente estudado foi coletado na Estação de Tratamento de Esgoto(ETE) Jardim das Flores, cujas coordenadas são 22²2'42,9”'S e 47³5'19,2”O, localizada em uma cidade situada na região central do estado de São Paulo, a $173 \mathrm{Km}$ da capital. A cidade possui uma população de 201.473 habitantes (IBGE, 2016), e o fornecimento de água e esgoto do município é realizado por uma empresa público-privada, com capacidade para suprir $100 \%$ da demanda. O total da rede de água é de 642 km, com 50.300 ligações. A rede de esgoto atende cerca de $98 \%$ da cidade, somando $633 \mathrm{~km}$ com 49.800 ligações. Entretanto, somente 30\% do esgoto é tratado.

Os mananciais que abastecem a cidade são os rios Corumbataí e Ribeirão Claro (Figura 1), caracterizados como rios de classe II, segundo a Resolução do Conselho Nacional do Meio Ambiente - CONAMA 20/1986. O Ribeirão Claro é um dos principais afluentes do rio Corumbataí, cuja bacia tem grande importância regional quanto ao abastecimento doméstico e industrial para os municípios integrantes da mesma, como também para outros pertencentes a bacias vizinhas (PALMA-SILVA et al., 2007).

A ETE Jardim das Flores tem uma área de $40.000 \mathrm{~m}^{2}$ e possui tratamento com reatores de lodos ativados simplificador e desinfecção

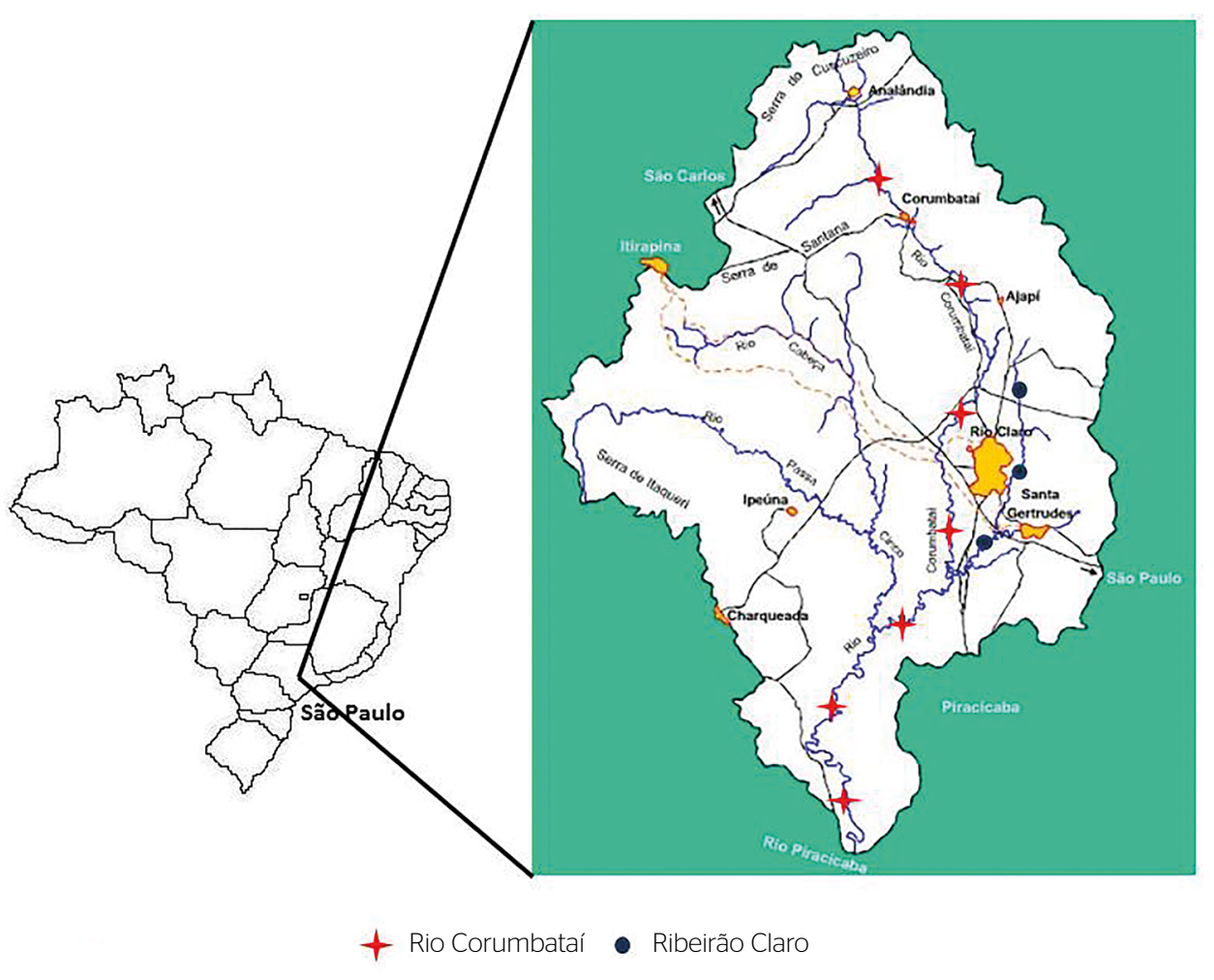

Figura 1 - Localização dos mananciais responsáveis pelo abastecimento de água e despejo de efluentes da cidade de Rio Claro (SP). Esquema adaptado do Comitê das Bacias Hidrográficas dos Rios Piracicaba, Capivari e Jundiaí (CBH-PCJ). 
final. O esgoto coletado é tratado por meio do sistema UASB (Upflow Anaerobic Sludge Blanket Reactor). A Figura 2 mostra o fluxograma simplificado do tratamento de esgoto utilizado pela estação.

$\mathrm{O}$ esgoto chega à ETE, passa pelo extravasor e pela grade grossa. A seguir, há a passagem pela elevatória, onde ocorre a sucção e a dosagem de álcalis pelas bombas re-autoescorvantes. O esgoto segue, então, para o conjunto de grade fina e caixa retentora. A grade fina, com abertura de $1 \mathrm{~cm}$, tem abaixo dela a caixa retentora de areia, de fluxo vertical e aerada. $\mathrm{O}$ material descartado da caixa retentora de areia tem acesso ao "leito de drenagem", e o líquido drenado, por sua vez, segue novamente para o fluxograma de tratamento de esgoto. Na caixa de drenagem, há um sistema de exaustão e tratamento de gases. Na saída da caixa retentora, há a introdução de lodo do sistema aeróbio. O material degradado e o efluente líquido do reator seguem para os reatores anaeróbios. Há a adição do excesso de lodo do sistema de tratamento aeróbio. O lodo descartado dos reatores tem acesso a um poço de sucção, onde sofre desidratação. Os gases coletados são destinados ao queimador, enquanto os gases exalados na superfície dos reatores são encaminhados para o reator de leito fixo, para seu devido tratamento. Após esse processo, os efluentes dos reatores anaeróbios têm acesso ao tanque de aeração complementar. Desses tanques, os efluentes passam por decantadores secundários. O lodo sedimentado é acumulado em tubulações perfuradas e, posteriormente, é removido com o auxílio de bombas helicoidais. O lodo gerado é recalcado: parte ao tanque de aeração; e o excesso à saída da caixa retentora de areia. Os efluentes decantados passam por sistema de desinfecção com radiação ultravioleta. O lodo descartado dos reatores anaeróbios é conduzido a um poço de sucção, de onde é recalcado para centrífuga, para reduzir a umidade. Esse lodo é tratado com cal. Os efluentes tratados são conduzidos até o corpo receptor - o rio Corumbataí - por meio de dutos providos de degraus e ventilados para que, ao alcançar o rio, a concentração de oxigênio dissolvido (OD) seja superior a $5 \mathrm{mg} / \mathrm{L}$. No percurso até o rio, o efluente é mantido aerado com alguns degraus. Parte do efluente tratado é recalcada até reservatório elevado para posterior utilização. Os efluentes não podem ser destinados ao consumo humano ou dessedentação de animais.

A capacidade da ETE é de ordem de $132 \mathrm{~L} / \mathrm{s}$. O sistema é monitorado mensalmente com análise de todos os parâmetros exigidos pela Companhia Ambiental do Estado de São Paulo (CETESB), que também monitora o rio Corumbataí no ponto de lançamento.

\section{Coleta do Efluente}

O efluente utilizado neste estudo é caracterizado, segundo a ETE Jardim das Flores, como esgoto doméstico. A coleta foi feita em frascos de plástico, em dois pontos distintos: na chegada do esgoto na estação e na saída do esgoto tratado. As amostras coletadas foram levadas ao Departamento de Bioquímica da Universidade Estadual Paulista "Júlio de Mesquita Filho" (UNESP) de Rio Claro, onde permaneceram a $4^{\circ} \mathrm{C}$ até o início dos experimentos. Foram realizadas duas coletas: uma no período chuvoso e outra no período seco, nos meses de abril e junho, respectivamente. Para as duas coletas, foram determinadas as variáveis: demanda bioquímica de oxigênio (DBO); demanda química de oxigênio (DQO); sólidos fixos, voláteis e sedimentáveis.

\section{Material Biológico}

O organismo teste utilizado no experimento foram peixes da espécie Oreochromis niloticus (Perciformes, Cichlidae), popularmente conhecidos como "tilápia do Nilo". Indivíduos com um tamanho médio de $15 \mathrm{~cm}$ foram analisados, a fim de evitar diferenças intraespecíficas relacionadas ao tamanho e à idade. Os animais, criados em piscicultura, no campus de São José do Rio Preto (SP) da UNESP, foram trazidos para o Laboratório de Toxicidade de Águas, do campus de Rio Claro (SP) da universidade, onde foram aclimatados em tanques com filtragem e aeração, à temperatura média de $23^{\circ} \mathrm{C}$.

\section{Bioensaio}

Para a montagem dos bioensaios, foram necessários três aquários, com capacidade de 20 L cada: um aquário continha apenas água de poço artesiano, utilizado como controle negativo; o segundo continha amostra de esgoto bruto (entrada na ETE); e o terceiro, a amostra de esgoto tratado. Na coleta da estação seca (junho), houve mortandade dos peixes expostos ao esgoto bruto. Portanto, para a montagem dos bioensaios, foi necessário diluir o esgoto bruto em água de poço artesiano, na proporção 7:5. Foram distribuídos cinco peixes em cada aquário, os quais permaneceram nessas condições por $72 \mathrm{~h}$. Tais procedimentos foram seguidos para que fossem estimados os efeitos dos possíveis contaminantes encontrados no esgoto bruto e no tratado.

\section{Teste do micronúcleo associado às anormalidades nucleares}

Aproximadamente $0,3 \mathrm{~cm}^{3}$ de sangue foram retirados de cada animal, por meio de punção cardíaca, utilizando seringas heparinizadas. Após a punção, a primeira gota foi descartada, a fim de evitar a contaminação do sangue por fluidos corpóreos. Gotas posteriores foram utilizadas para a confecção das lâminas por meio da técnica de esfregaço sanguíneo. Três esfregaços foram realizados para cada indivíduo. $\mathrm{O}$ material foi fixado em metanol absoluto por 10 min e, após $24 \mathrm{~h}$, as lâminas foram hidrolisadas em $\mathrm{HCl} 1 \mathrm{~N}$, por $11 \mathrm{~min}$, em banho-maria à $60^{\circ} \mathrm{C}$. Em seguida, as lâminas foram lavadas em água destilada e submetidas ao reativo de Schiff, por $2 \mathrm{~h}$.

Um total de 3.000 eritrócitos foi analisado para cada peixe (1.000 eritrócitos/lâmina), sob objetiva de imersão (aumento de 1000 x). A soma total de eritrócitos portadores de anormalidades nucleares e micronúcleos foi quantificada e classificada de acordo com Carrasco et al. (1990). O teste estatístico utilizado para a comparação dos resultados entre os grupos foi o teste ANOVA de um critério, com $\mathrm{p}<0,05$. 


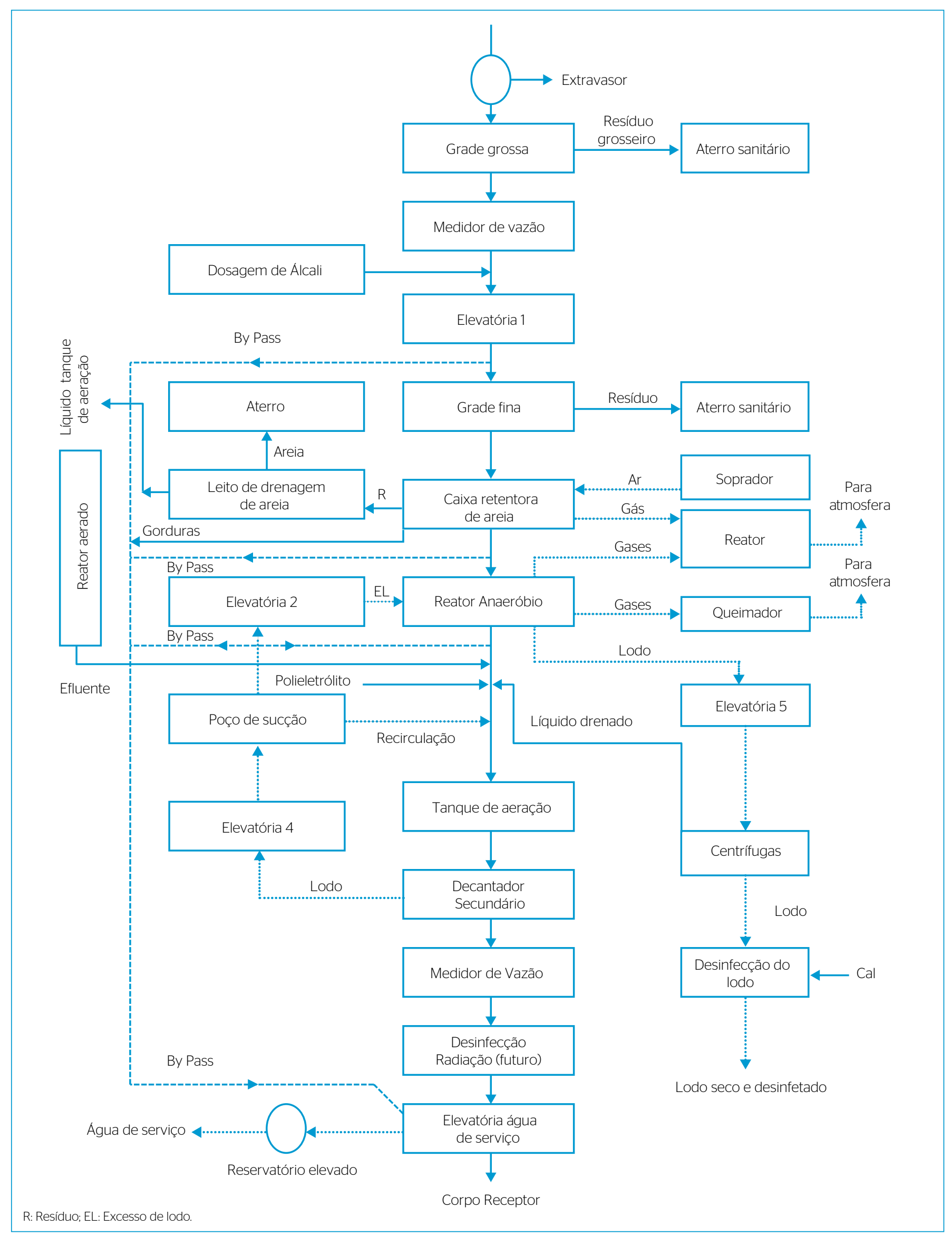

Figura 2 - Fluxograma da Estação de Tratamento de Esgoto Jardim das Flores, Rio Claro-SP. 


\section{RESULTADOS}

Em ambos os meses de coleta, foram mensurados dados relacionados a parâmetros físico-químicos para o esgoto bruto e o tratado (Tabela 1). O esgoto bruto apresentava coloração marrom clara e odor desagradável. Após tratamento, o efluente era quase inodoro e sua coloração bem mais clara, mas não límpida.

A análise da frequência de eritrócitos micronucleados (seta na Figura 3A) de O. niloticus, após exposição às amostras da estação chuvosa, demonstrou valores que não foram estatisticamente significativos para micronúcleos, entre quaisquer tratamentos (Tabela 2). Em contrapartida, na estação seca, foram observados valores estatisticamente significativos para a frequência de micronúcleos, nas comparações entre o controle e o esgoto bruto, bem como entre o esgoto bruto e o tratado (Tabela 2).

O teste empregado propiciou a observação de vários tipos de anormalidades nucleares, analisadas e classificadas de acordo com Carrasco et al. (1990). Foram observadas células portadoras de brotos nucleares (cabeças de setas nas Figuras 3A e 3B), de núcleos do tipo "brokken-egg" (seta na Figura 3C), "notched" (seta na Figura 3D), "lobed" (asteriscos nas Figuras 3A e 3D) e "blebbed" (seta na Figura 3E). Foram observados, ainda, microcito em formação (seta na Figura 3B), microcito (seta na Figura 3F) e retração do núcleo (cabeça de seta na figura 3F). $\mathrm{Na}$ estação chuvosa, a frequência das anormalidades observadas foi significativa entre o controle e a amostra de esgoto bruto (Tabela 2). $\mathrm{Na}$ estação seca, as frequências observadas também foram significativas nas comparações entre o controle e o esgoto bruto e entre o controle e o esgoto tratado, bem como entre o esgoto bruto e o tratado (Tabela 2). Células portadoras de microcito foram observadas somente para essa estação.

\section{DISCUSSÃO}

O esgoto não tratado é uma fonte comum de poluição para o ambiente aquático. Estudos demonstram que esse tipo de despejo urbano é uma mistura de agentes químicos e biológicos que interagem entre si (AKAISHI, 2007). Metais (GAGNON et al., 2006), produtos farmacêuticos (MIAO et al., 2004; JJEMBA, 2006), hidrocarbonetos policíclicos aromáticos (HOEGER et al., 2004; ALONSO et al., 2005), pesticidas (MANTIS et al., 2005) e compostos derivados do nitrogênio e fósforo são os principais grupos de substâncias químicas já detectadas em esgoto bruto e tratado (AKAISHI, 2007).

Ainda de acordo com AKAISHI (2007), a interação desses compostos químicos entre si e aos fatores ambientais (temperatura, salinidade, sedimento) cria incontáveis combinações de substâncias e reações, as quais podem provocar sérios efeitos na biota aquática.

Apenas nos últimos anos é que alguns estudos foram realizados expondo organismos ao esgoto tratado e ao não tratado (GRISOLIA \& STARLING, 2001; HOEGER et al., 2004; DINIZ et al., 2005). Semelhante ao que foi realizado no presente estudo, o teste do micronúcleo foi aplicado por Grisolia e Starling (2001), em três espécies de peixes, Oreochromis niloticus, Tilapia rendalli e Cyprinus carpio, para avaliar a capacidade de indução de danos genéticos pela descarga de duas estações de tratamentos de águas, que são lançadas no lago Paranoá (DF). Os autores observaram a presença de eritrócitos micronucleados, embora não tenham encontrado diferenças significativas entre o controle e as áreas de despejo no lago.

Estudos realizados por Akaishi et al. (2007) observaram aumento da atividade fagocítica, na capacidade de resistir a patógenos e lesões histopatológicas nas brânquias de mexilhões expostos por 14 dias a esgoto doméstico.

Como visto, a exposição de organismos a agentes tóxicos e genotóxicos pode ocasionar diversas alterações histológicas bem como

Tabela 1 - Análise físico-química do efluente bruto e após tratamento, para as coletas realizadas.

\begin{tabular}{|c|c|c|c|c|c|c|}
\hline \multirow{2}{*}{ Parâmetros analíticos } & \multicolumn{3}{|c|}{ Estação chuvosa } & \multicolumn{3}{|c|}{ Estação seca } \\
\hline & Entrada & Saída do reator anaeróbio & Saída & Entrada & Saída do reator anaeróbio & Saída \\
\hline $\mathrm{DBO}(\mathrm{mg} / \mathrm{L})$ & 166 & 22 & 6 & 556 & 60 & 0,2 \\
\hline $\mathrm{DQO}(\mathrm{mg} / \mathrm{L})$ & 324 & 110 & 90 & 1400 & 112 & 15 \\
\hline $\mathrm{ST}(\mathrm{mg} / \mathrm{L})$ & 506 & 314 & 190 & 3238 & 428 & 118 \\
\hline STF (mg/L) & 280 & 118 & 68 & 326 & 280 & 60 \\
\hline $\mathrm{STV}(\mathrm{mg} / \mathrm{L})$ & 226 & 196 & 122 & 2912 & 148 & 58 \\
\hline SST (mg/L) & 108 & ND & 36 & 1812 & 90 & 6 \\
\hline $\mathrm{SSF}(\mathrm{mg} / \mathrm{L})$ & 12 & ND & ND & 138 & 18 & ND \\
\hline SSV (mg/L) & 96 & ND & 36 & 1674 & 72 & 6 \\
\hline $\mathrm{SDT}(\mathrm{mg} / \mathrm{L})$ & 398 & 314 & 154 & 1426 & 338 & 112 \\
\hline $\mathrm{SDF}(\mathrm{mg} / \mathrm{L})$ & 268 & 118 & 68 & 188 & 262 & 60 \\
\hline $\mathrm{SDV}(\mathrm{mg} / \mathrm{L})$ & 130 & 196 & 86 & 1238 & 76 & 52 \\
\hline
\end{tabular}

ND: Não detectado, valor inferior ao limite máximo permitido (VMP); DBO: demanda bioquímica de oxigênio; DQO: demanda química de oxigênio; ST: sólidos totais; STF: sólidos totais fixos; STV: sólidos totais voláteis; SST: sólidos suspensos totais; SSF: sólidos suspensos fixos; SSV: sólidos suspensos voláteis; SDT: sólidos dissolvidos totais; SDF: sólidos dissolvidos fixos; SDV: sólidos dissolvidos voláteis. 
citogenéticas. Nesse sentido, o presente estudo observou um grande número de alterações nucleares nos eritrócitos dos peixes expostos ao esgoto bruto e diluído de uma cidade do interior do estado de São Paulo, a qual apresenta somente cerca de $30 \%$ de seu esgoto tratado.

Nos centros urbanos, a composição do esgoto reflete os hábitos de vida da população e a frequência com que novos tipos de contaminantes são criados e lançados no ambiente. Um estudo aprofundado para caracterizar todas as substâncias presentes no esgoto da ETE estudada acaba se tornando inviável devido ao elevado custo das análises químicas. Entretanto, de acordo com a literatura científica, o esgoto doméstico apresenta, além do alto teor de matéria orgânica e patógenos, contaminantes utilizados em grandes quantidades em nosso cotidiano, como produtos de higiene pessoal, limpeza doméstica e medicamentos.

Os parâmetros químicos corroboram a presença de contaminação resultante do despejo de origem doméstica, dado os elevados valores de DBO, DQO e sólidos totais aqui observados. Todavia, após tratamento, nota-se uma redução desses valores, demonstrando a eficiência do tratamento utilizado.

Os dados obtidos neste estudo mostraram efeitos genotóxicos e mutagênicos do efluente bruto, em ambas as coletas, embora um número maior de micronúcleos e anormalidades tenha sido observado no mês de junho, representando o mês de estiagem na região. A sazonalidade, provavelmente, influenciou nos resultados obtidos; devido

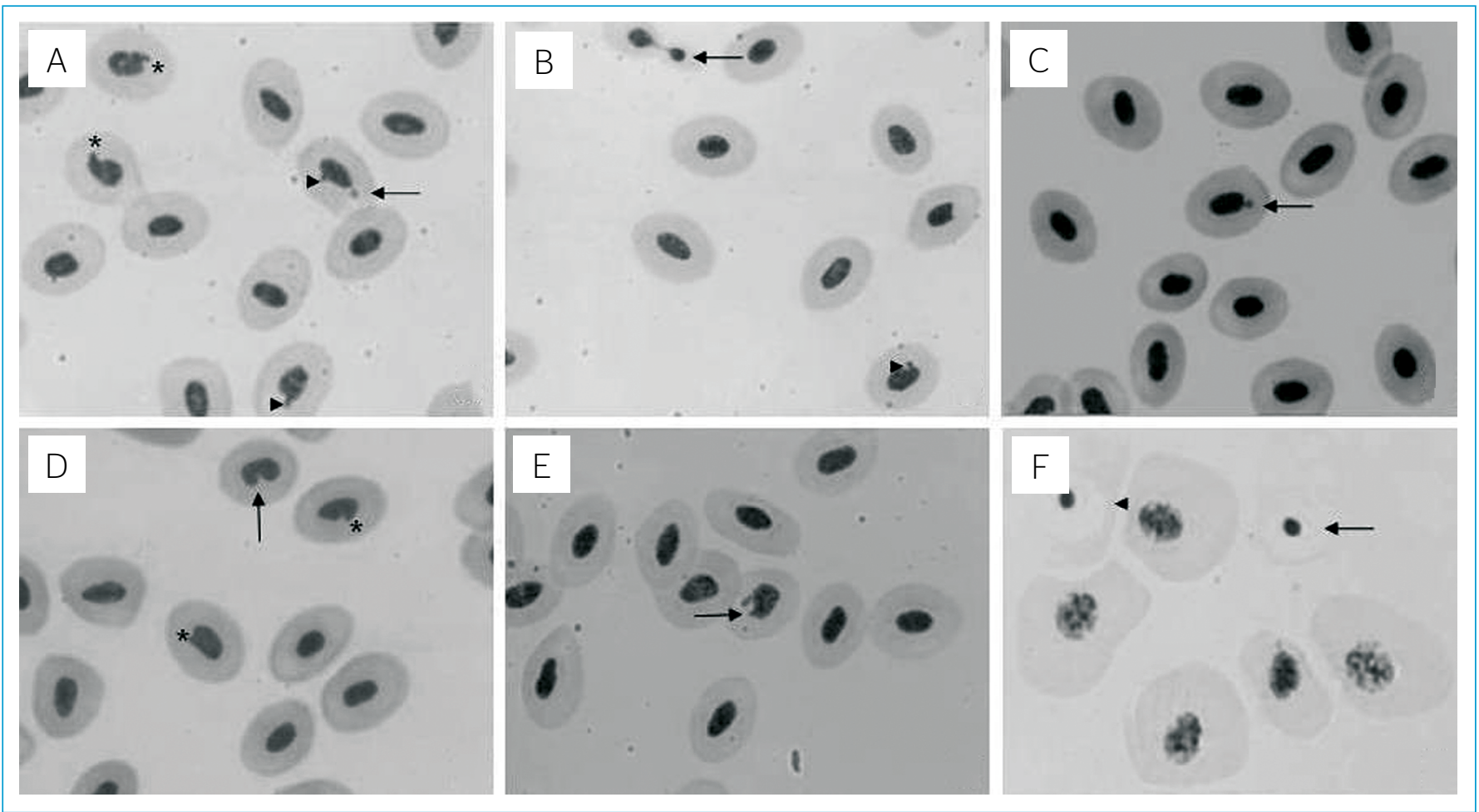

Figura 3 - Micronúcleo e anormalidades nucleares encontradas em eritrócitos de Oreochromis niloticus, após 72 h de exposição ao esgoto doméstico. A) Micronúcleo (seta), broto nuclear (cabeça da seta) e núcleos do tipo "lobed" (asterisco); B) broto nuclear (cabeça da seta) e microcito em formação (seta); C) núcleo do tipo "broken-egg" (seta); D) núcleo do tipo "notched" (seta) e do tipo "lobed" (asterisco); E) núcleo do tipo "blebbed" (seta); F) microcito (seta) e retração do núcleo (cabeças da seta).

Tabela 2 - Número total de anormalidades nucleares e micronúcleos observados em eritrócitos de $O$. niloticus expostos a um efluente bruto e após tratamento, nas coletas realizadas.

\begin{tabular}{|c|c|c|c|c|c|c|c|c|c|c|}
\hline Período de coleta & Ponto & Total de eritrócitos analisados & EB & EP & BN & $\mathrm{MC}$ & BK & BLN & MN & Total de alterações \\
\hline \multirow{3}{*}{ Estação chuvosa } & $\mathrm{CN}$ & 15000 & $\mathrm{O}$ & 0 & 6 & O & 1 & 66 & $\mathrm{O}$ & 73 \\
\hline & Bruto & 15000 & 1 & $\mathrm{O}$ & 13 & $\mathrm{O}$ & $\mathrm{O}$ & 168 & 2 & $184^{*}$ \\
\hline & Tratado & 15000 & O & 1 & 7 & O & 0 & 72 & 2 & 82 \\
\hline \multirow{3}{*}{ Estação seca } & $\mathrm{CN}$ & 15000 & 3 & $\mathrm{O}$ & 5 & $\mathrm{O}$ & 1 & 94 & 2 & 105 \\
\hline & Bruto & 15000 & 3 & 3 & 24 & 32 & $\mathrm{O}$ & 427 & 37 *a & $526 * b$ \\
\hline & Tratado & 15000 & $\mathrm{O}$ & 0 & 10 & 4 & 0 & 154 & $77^{\star a}$ & $175^{* b}$ \\
\hline
\end{tabular}

CN: controle; EB: eritrócitos binucleados; EP: eritrócitos polinucleados; BN: broto nuclear; MC: microcito; BK: núcleo "broken-egg"; BLN: somatória dos eritrócitos portadores de núcleos dos tipos "blebbed", "lobed" e "notched"; MN: micronúcleos; *diferiram significativamente em relação ao CN (p<0,05), pelo teste ANOVA; ab: diferiram significativamente na comparação entre o efluente bruto e o tratado. 
à escassez de chuvas, pode ter ocorrido uma maior concentração dos poluentes neste período.

Micronúcleos são pequenas massas intracitoplasmáticas de cromatina com aparência de um pequeno núcleo, resultantes de quebras cromossômicas ou aneuploidia durante a divisão celular (HEDDLE et al., 1983; AL-SABTI \& METCALF, 1995; GRISOLIA \& STARLING, 2001). São resultantes da ação de compostos clastogênicos e/ou aneugênicos. A presença de micronúcleos nos eritrócitos de peixes expostos a tais efluentes indica a presença de substâncias capazes de induzir danos ao material genético desses organismos.

Dados recentes têm demonstrado uma relação entre as anormalidades nucleares e a instabilidade genômica (SERRANO-GARCIA \& MONTERO-MONTOYA, 2001; FENECH \& CROTT, 2002). Alguns autores acreditam que as anormalidades nucleares estejam diretamente associadas à formação de micronúcleos (FENECH et al., 1999). Todavia, ainda não foram esclarecidos os mecanismos exatos de formação dessas células com morfologia nuclear alterada em peixes.

O broto nuclear, por exemplo, seria a primeira alteração nuclear originada em resposta à ação de determinado agente; sendo esta intensificada, haveria a formação de um fio, originando o broken-egg e, posteriormente, o fio sofreria um rompimento, formando o micronúcleo.

De acordo com Shimizu et al. (2000), a formação dessas anormalidades representa um mecanismo por meio do qual a célula elimina o material genético amplificado. Eventualmente, um micronúcleo poderia ser expulso da célula, na forma de um microcito. Dessa maneira, a formação de microcitos caracteriza uma estratégia de manutenção da integridade celular, pela eliminação do material genético excedente (SOUZA \& FONTANETTI, 2006).

Após tratamento do esgoto aqui estudado, observou-se que a frequência de micronúcleos e anormalidades nucleares diminuiu, sugerindo uma melhor qualidade do efluente após tratamento. Consequentemente, o tratamento pode minimizar os impactos ambientais causados pelo despejo do efluente.

Todavia, um monitoramento contínuo, mais coletas, análises físico-químicas e bioensaios com os mais diversificados organismos teste devem ser realizados para estimar com precisão os reais impactos que os efluentes domésticos, tratados ou não, podem causar aos organismos expostos a eles.

\section{CONCLUSÃO}

Diante dos resultados obtidos, corrobora-se a importância da realização de estudos como este, e acredita-se que a avaliação da eficiência no tratamento do esgoto doméstico, por meio de testes biológicos, constitui uma ferramenta fundamental na garantia da qualidade de vida da população e no auxílio à preservação do meio ambiente. Nesse sentido, sugere-se que o tratamento realizado pela ETE Jardim das Flores foi eficiente na remoção de substâncias genotóxicas e mutagênicas e na minimização do efeito destas sobre os organismos expostos.

\section{AGRADECIMENTO}

As autoras agradecem às agências CNPq e FUNDUNESP, que fomentaram o estudo.

\section{REFERÊNCIAS}

AKAISHI, F.M. (2007) Evaluation of toxicity of wastewater treated and untreated into the marine bivalve Mytilus edulis. 133p. Tese (Doutorado) - Universidade Federal do Paraná, Curitiba. Disponível em: <http:// dspace.c3sl.ufpr.br/dspace/handle/1884/10699>. Acesso em: 23 jul. 2011.

AKAISHI, F.M.; ST-JEAN, S.D; BISHAY, F; CLARKE, J:; RABITTO, I.S.; RIBEIRO, C.A.O. (2007) Immunological responses, histopathological finding and disease resistance of blue mussel (Mytilus edulis) exposed to treated and untreated municipal wastewater. Aquatic Toxicology, v. 82, p. 1-14.

ALONSO, M.C.; TIRAPU, L.; GINEBREDA, A.; BARCELÓ, D. (2005) Monitoring and toxicity of sulfonated derivatives of benzene and naphthalene in municipal sewage treatment plants. Environmental Pollution, v. 137, p. 253-262.

AL-SABTI, K. \& METCALF, C.D. (1995) Fish micronuclei for assessing genotoxicity in water. Mutation Research, v. 343, p. 121-135.

AYLLÓN, F. \& GARCIA-VASQUEZ, E. (2000) Induction of micronuclei and other nuclear abnormalities in European minnow Phoxinus phoxinus and mollie Poecilia latipinna: an assessment of fish miscronucleus test. Mutation Research, v. 467, p. 177-186.
CARRASCO, K.R.; TILBURY, K.L.; MAYERS, M.S. (1990) Assessment of the piscine micronuclei test as in situ biological indicator of chemical contaminants effects. Canadian Journal of Fisheries and Aquatic Science, v. 47, p. 2123-2136.

ÇAVAS, T. \& ERGENE-GÖZÜKARA, S. (2003) Micronuclei, nuclear lesions and interphase silver-stained nucleolar regions (AgNORs) as cyto-genotoxicity indicators in Oreochromis niloticus exposed to textile mill effluent. Mutation Research, v. 538, p. 81-91.

ÇAVAS, T. \&ERGENE-GÖZÜKARA, S. (2005) Induction of micronuclei and nuclear abnormalities in Oreochromis niloticus following exposure to petroleum refinery and chromium processing plant effluents. Aquatic Toxicology, v. 74, 264-271.

CHRISTOFOLETTI, C.A. (2008) Avaliação do potencial citotóxico, genotóxico e mutagênico das águas de um ambiente lêntico por meio dos sistemas-teste de Allium cepa e Oreochromis niloticus. 118p. Dissertação (Mestrado) - Universidade Estadual Paulista "Júlio de Mesquita Filho", São Paulo. Disponível em: <http://www. dominiopublico.gov.br/pesquisa/DetalheObraForm.do?select action=\&co_obra=118067>. Acesso em: 20 jul. 2011. 
CONAMA - Conselho Nacional do Meio Ambiente. Resolução 20/1986. Disponível em: http://www.mma.gov.br/port/conama/res/ res86/res2086.html Acesso em 03 de julho de 2011.

DAVID, J.A.O. \& FONTANETTI, C.S. (2005) Surface morphology of Mytella falcata gill filaments from three regions of the Santos Estuary. Brazilian Journal of Morphological Sciences, v. 22, p. 203-210.

DINIZ, M.S.; PERES, I.; PIHAN, J.C. (2005) Comparative study of the estrogenic responses of mirror carp (Cyprinus carpio) exposed to treated municipal sewage effluent (Lisbon) during two periods in different seasons. Science of Total Environmental, v. 349, p. 129-139.

FENECH, M. (2000) The in vitro micronucleus technique. Mutation Research, v. 455, p. 81-95.

FENECH, M. \& CROTT, J.W. (2002) Micronuclei, nucleoplasmic bridges and nuclear buds induced in folic acid deficient human lymphocytes - evidence for breakage-fusion-bridge cycles in the cytokinesis-block micronucleus assay. Mutation Research, v. 504 , p. 131-136.

FENECH, M.; HOLLAND, N.; CHANG, W.P.; ZEIGER, E.; BONASSI, S. (1999) The Human MicroNucleus Project: an international collaborative study on the use of the micronucleus technique for Measuring DNA damage in humans. Mutation Research, v. 428, p. 271-283.

FONTANETTI, C.S.; SOUZA, T.S.; CHRISTOFOLETTI, C.A. (2012) The role of biomonitoring in the quality assessment of water resources. In: BILIBIO, C.; HENSEL, O.; SELBACH, J. Sustainable water management in the tropics and subtropics and cases study in Brazil. Brasil/Alemanha: UNIPAMPA/UNIKASSEL. v. 3. p. 975-1005.

GAGNON, C.; GAGNÉ, F.; TURCOTTE, P.; SAULNIER, I.; BLAISE, C.; SALAZAR, M.H.; SALAZAR, S.M. (2006) Exposure of caged mussels to metals in a primary-treated municipal wastewater plume. Chemosphere, v. 62, p. 998-1010.

GRISOLIA, C.K. \& STARLING, F.L.R.M. (2001) Micronuclei monitoring of fishes from Lake Paranoá, under influence of sewage treatment plant discharges. Mutation Research, v. 491, p. 39-44.

HAM, A.W. \& CORMACK, D.H. Histologia. 9 ed. Rio de Janeiro: Guanabara Koogan, 1991. 570p.

HEDDLE, J.A.; HITE, M.; JRKHART, B.; MACGREGOR, J.T.; SALAMONE, M.F. (1983) The induction of micronuclei as a measure of genotoxicity. Mutation Research, v. 123, p. 61-118.

HOEGER, B.; VAN DEN HEUVEL, M.R.; HITZFELD, B.C.; DIETRICH, D.R. (2004) Effects of treated sewage on immune function in rainbow trout (Oncorhynchus mykiss). Aquatic Toxicology, v. 70, p. 345-355.

HOSHINA, M.M.; ANGELIS, D.F.; MARIN-MORALES, M.A. (2008) Induction of micronucleus and nuclear alterations in fish (Oreochromis niloticus) by a petroleum refinery effluent. Mutation Research, v. 656, p. 44-48.

IBGE - Instituto Brasileiro de Geografia e Estatística (2016). Cidades. Disponível em: http://cidades.ibge.gov.br/xtras/perfil.php? codmun=354390 . Acesso: 19 jan. 2017.
JJEMBA, P.K. (2006) Excretion and ecotoxicity of pharmaceuticals and personal care products in the environment. Ecotoxicology and Environmental Safety, v. 63, p. 113-130.

MANTIS, I.; VOUTSA, D.; SAMARA, C. (2005) Assessment of the environmental hazard from municipal and industrial wastewater treatment sludge by employing chemical and biological methods. Ecotoxicology and Environmental Safety, v. 62, p. 397-407.

MARIA, V.L.; CORREIA, A.C.; SANTOS, M.A. (2003) Genotoxic and hepatic biotransformation responses induced by the overflow of pulp mill and secondary treated effluents on Anguilla Anguilla $L$. Ecotoxicology and Environmental Safety, v. 55, p. 126-137.

MATSUMOTO, S.T.; MANTOVANI, M.S.; MALAGUTTI, M.I.A.; DIAS, A.L.; FONSECA, I.C.; MARIN-MORALES, M.A. (2006) Genotoxicity and mutagenicity of water contaminated with tannery effluents, as evaluated by the micronucleus test and comet assay using the fish Oreochromis niloticus and chromosome aberrations in onion root-tips. Genetics Molecular Biology, v. 29, p. 148-158.

MIAO, X.; BISHAY, F.; CHEN, M.; METCALFE, C.D. (2004) Occurrence of antimicrobials in the final effluent of wastewater treatment plants in Canada. Environmental Science Technology, v. 38, p. 3533-3541.

MINISSI, S.; CICCOTTI, E.; RIZZONI, M. (1996) Micronucleus test in erythrocytes of Barbus plebejus (Teleostei, Pisces) from two natural environments: a bioassay for the in situ detection of mutagens in freshwater. Mutation Research, v. 367, p. 245-251.

MORAES, D.S.L. \& JORDÃO, B.Q. (2002) Water resources deterioration and its impact on human health. Saúde Pública, v. 36, p. 370-374.

PALMA-SILVA, G.M.; TAUK-TORNISIELO, S.M.; PIÃO, A.C. (2007) Purification capacity of a segment of Corumbataí river, SP, Brazil. Holos Environment, v. 7, p. 139-153.

RUSSO, C.; ROCCO, L.; MORESCALCHI, M.A.; STINGO, v. (2004) Assessment of environmental stress by the micronucleus test and the comet assay on the genome of teleost populations from two natural environments. Ecotoxicology and Environmental Safety, v. 57 , p. $168-174$

SERRANO-GARCIA, L. \& MONTERO-MONTOYA, R. (2OO1) Micronuclei and chromatine buds are related genotoxic events. Environmental and Molecular Mutagenesis, v. 38, p. 38-45.

SHIMIZU, N.; SHIMUARA, T.; TANAKA, T. (2000) Selective elimination of acentric double minutes from cancer cells through the extrusion of micronuclei. Mutation Research, v. 448, p. 81-90.

SOUZA, T.S. \& FONTANETTI, C.S. (2006) Micronucleus test and observation of nuclear alterations in erythrocytes of Nile tilapia exposed to waters affected by refinery effluent. Mutation Research, v. 605, p. $87-93$.

VENTURA, B.C.; ANGELIS, D.F.; MARIN-MORALES, M.A. (2008) Mutagenic and genotoxic effects of the Atrazine herbicide in Oreochromis niloticus (Perciformes, Cichlidae) detected by the micronuclei test and the comet assay. Pesticide Biochemistry and Physiology, v. 90, p. 42-51. 